Revista Brasileira de Agricultura Irrigada v.10, nº.6, p. 1075 - 1085, 2016

ISSN 1982-7679 (On-line)

Fortaleza, CE, INOVAGRI - http://www.inovagri.org.br

DOI: $10.7127 /$ rbai.v10n600538

Protocolo 538.16 - 27/11/2016 Aprovado em 20/12/2016

\title{
PRODUTIVIDADE DE TOMATEIROS IRRIGADOS COM ÁGUA RESIDUÁRIA DE SUINOCULTURA
}

\author{
Rannaiany Teixeira Manso ${ }^{1}$, Daniely Karen Matias Alves ${ }^{2}$, Frederico Antonio Loureiro \\ Soares $^{3}$, Fernando Nobre Cunha ${ }^{4}$, Marconi Batista Teixeira ${ }^{5}$, Wilker Alves Morais ${ }^{6}$
}

\section{RESUMO}

No Brasil, a cultura do tomate ocupa lugar de destaque na economia, não somente pelo seu valor econômico, mas também por ser uma atividade geradora de grande número de empregos. Assim, objetivou-se com este estudo avaliar as características de produtividade e pós-colheita de tomateiros (variedade Santa Clara), irrigados com água residuária de suinocultura. O delineamento experimental utilizado foi o de blocos casualizados, em esquema fatorial (5 x 2), com cinco repetições totalizando cinquenta unidades experimentais. Os tratamentos foram: 100\% água residuária bruta; 100\% água residuária filtrada em filtro de areia; 100\% água SODIS (Solar disinfection); $50 \%$ da água residuária filtrada e 50\% com água SODIS; água de abastecimento (testemunha) e duas épocas de avaliações 100 e 120 DAP (dias após o plantio). A água residuária utilizada foi coletada na granja de suinocultura do IFGoiano - Campus Rio Verde e devidamente transportada em recipientes de $100 \mathrm{~L}$ para o local de execução do experimento. As variáveis analisadas foram: número de frutos, peso dos frutos, comprimento dos frutos, diâmetro dos frutos, número de botões florais e produtividade do tomate. A produtividade é maior para o tratamento 100\% água residuária bruta com diferença de até $60 \%$ quando comparada com a água de abastecimento.

Palavras-chave: Solanum lycopersicum, tratamento de dejetos, qualidade da água.

\section{PRODUCTIVITY OF TOMATOES IRRIGATED WITH SWINE WASTEWATER}

\footnotetext{
${ }^{1}$ Graduanda em Engenharia Ambiental, Instituto Federal Goiano - Campus Rio Verde, Rodovia Sul Goiana, Km 01, CEP: 75.901-170, Rio Verde - GO, e-mail: rannaiany@hotmail.com

${ }^{2}$ Graduanda em Engenharia Ambiental, IFGoiano - Campus Rio Verde, e-mail: daniely_karen@hotmail.com ${ }^{3}$ Eng. Agrônomo, Prof. Dr. em Agronomia, IFGoiano - Campus Rio Verde, e-mail: fredalsoares@hotmail.com ${ }^{4}$ Doutorando em Ciências Agrárias - Agronomia, IFGoiano - Campus Rio Verde, e-mail: fernandonobrecunha@hotmail.com

${ }^{5}$ Eng. Agrônomo, Prof. Dr. em Agronomia, IFGoiano - Campus Rio Verde, e-mail: marconibt@gmail.com ${ }^{6}$ Doutor em Ciências Agrárias - Agronomia, IFGoiano - Campus Rio Verde, e-mail: wilker.alves.morais@gmail.com
} 


\begin{abstract}
In Brazil, tomato culture occupies a place of highlights in the economy, not only because of its economic value, but also because it generates a large number of jobs. The objective of this study was to evaluate the characteristics of productivity and post-harvest of tomato plants (Santa Clara variety) irrigated with swine wastewater. The experimental design was randomized blocks, in a factorial scheme $(5 \times 2)$, with five replications totaling fifty plots. The treatments were: $100 \%$ raw waste water, $100 \%$ filtered waste water, $100 \%$ SODIS (Solar disinfection) water, $50 \%$ filtered wastewater and 50\% SODIS water; water supply (control) and two evaluation periods 100 and 120 DAP (days after planting). The used wastewater was collected at the IFGoiano - Campus Rio Verde and duly transported in $100 \mathrm{~L}$ containers to the local of experiment. The variables obtained were: number of fruits, fruit weight, fruit length, fruit diameter, number flower buds and productivity of tomato. Productivity is higher for $100 \%$ raw wastewater with difference up to $60 \%$ when compared to the water supply.
\end{abstract}

Keywords: Solanum lycopersicum, waste treatment, water quality.

\section{INTRODUÇÃO}

No Brasil, a cultura do tomate ocupa lugar de destaque na economia, não somente pelos seus benefícios socioambientais e seu valor econômico, mas também por ser uma atividade geradora de grande número de empregos (SOUZA et al., 2010; MACHADO NETO, 2014). O tomateiro é uma das hortaliças de fruto mais importantes comercialmente, com uma produção anual de 3,2 e 3,4 milhões de toneladas, numa área plantada de 63.000 e 54.051 ha, no ano de 2008 e 2016 respectivamente. (AGRIANUAL, 2008; IBGE, 2016).

A produção do tomate é realizada durante a estação seca do ano, sendo a irrigação prática fundamental para suprir as necessidades hídricas das plantas (MAROUELLI, 2012), consequentemente há um custo muito elevado de água nesse período. A irrigação na cultura do tomate é de suma importância, de acordo com Alvarenga (2004) a escassez de água um pouco antes e durante o período de floração reduz o número de frutos. Silva et al. (2013) constataram que os menores diâmetros encontrados podem estar relacionados ao déficit hídrico, o qual afeta diretamente os processos fotossintéticos das plantas e, consequentemente, a produção.

O uso planejado de águas residuárias implica necessidade menor de captação dos recursos hídricos, constituindo-se, portanto, em estratégia eficaz para a conservação desse recurso natural (MEDEIROS et al., 2007), além de evitar que a falta de disponibilidade de água potável prejudique diretamente na necessidade hídrica dos tomateiros.

A prática de irrigação com o uso do efluente tratado de dejetos de suíno, permite a destinação ambientalmente correta dos efluentes gerados pela atividade, reduzindo assim os impactos negativos no meio ambiente (MEDEIROS et al., 2011). De acordo com Vielmo (2008) a água residuária de suinocultura, contém macro e micronutrientes, como nitrogênio, fósforo, potássio, cálcio, magnésio, ferro, zinco, cobre e outros, que podem contribuir para redução da aplicação de fertilizantes nas lavouras.

Segundo Sampaio et al. (2011) o peso dos frutos está diretamente relacionado ao manejo nutricional, época de plantio, cultivar, uso de irrigação, etc. Logo, o aproveitamento de águas residuárias ricas em nutrientes na fertirrigação de culturas agrícolas pode possibilitar aumento de produtividade e qualidade dos produtos colhidos, além de promover melhoria nas características químicas, físicas e biológicas do solo (SOUZA et al., 2010).

Assim, Objetivou-se com este estudo avaliar as características de produtividade e póscolheita de tomateiros (variedade Santa Clara), irrigados com água residuária de suínocultura.

\section{MATERIAL E MÉTODOS}


O experimento foi desenvolvido em uma casa de vegetação instalada no IFGoiano - Campus Rio Verde. A casa de vegetação possui o sistema de climatização (temperatura e umidade) por circulação e refrigeração de água, aeração controlada por exaustores, sistema de irrigação por aspersores e cortina de sombreamento, todos esses dispositivos são automatizados e são controlados por regulagem no painel de controle principal. As coordenadas geográficas do local de instalação do experimento são $17^{\circ} 48$ ' $23^{\prime \prime} \mathrm{S}$ e $50^{\circ} 54^{\prime} 11^{\prime}$ ' O, com altitude média de $744 \mathrm{~m}$.
O clima da região é classificado, conforme Köppen (2013), como Aw (tropical), com chuva nos meses de outubro a maio e seca nos meses de junho a setembro, ou seja, com chuva no verão e seca no inverno. A temperatura média anual varia de 20 a $35^{\circ} \mathrm{C}$, as precipitações variam de 1.500 a $1.800 \mathrm{~mm}$ anuais e o relevo é suave ondulado (5\% de declividade).

O solo foi classificado como Latossolo Vermelho distroférrico (LVdf), de textura média (EMBRAPA, 2013). As características químicas do solo estão apresentadas na Tabela 1.

Tabela 1. Características químicas do solo.

\begin{tabular}{|c|c|c|c|c|c|c|c|c|c|}
\hline & \multicolumn{9}{|c|}{ Características químicas $^{1}$} \\
\hline Prof. & $\mathrm{N}$ & $\mathrm{P}$ & K & $\mathrm{Ca}$ & $\mathrm{Mg}$ & $\mathrm{S}$ & $\mathrm{Al}$ & $\mathrm{H}+\mathrm{Al}$ & $\mathrm{pH}$ \\
\hline $\mathrm{m}$ & $\%$ & \multicolumn{2}{|c|}{$\mathrm{mg} \mathrm{dm} \mathrm{m}^{-3}$} & \multicolumn{2}{|c|}{$\mathrm{cmol}_{\mathrm{c}} \mathrm{dm}^{-3}$} & $\mathrm{mg} \mathrm{dm} \mathrm{dm}^{-3}$ & \multicolumn{2}{|c|}{$\mathrm{cmol}_{\mathrm{C}} \mathrm{dm}^{-3}$} & $\mathrm{CaCl}_{2}$ \\
\hline $0,00-0,20$ & 0,10 & 0,19 & 42,0 & 2,82 & 0,97 & 4,55 & 0,00 & 1,78 & 6,0 \\
\hline Prof. & $\mathrm{Na}$ & $\mathrm{Zn}$ & $\mathrm{B}$ & $\mathrm{Cu}$ & $\mathrm{Fe}$ & Mn & M.O & CTC & $\mathrm{V}$ \\
\hline $\mathrm{m}$ & \multicolumn{6}{|c|}{------------------------mg dm³3---------------------- } & $\mathrm{g} \mathrm{dm}^{-3}$ & \multicolumn{2}{|c|}{$\%$} \\
\hline $0,00-0,20$ & 0,00 & 1,23 & 0,07 & 1,97 & 37,54 & 40,65 & 24,9 & 5,68 & 68,7 \\
\hline
\end{tabular}

${ }^{1}$ Profundidade (Prof); Matéria orgânica (M.O); Capacidade de troca de cátions (CTC); Saturação por bases (V).

A água residuária utilizada foi coletada na granja de suinocultura do IFGoiano - Campus Rio Verde, devidamente transportada em recipientes de $100 \mathrm{~L}$ para o local de execução do experimento, onde foi submetida ao processo de filtragem, através de um filtro constituído com várias camadas de areia e brita e também ao processo de desinfeção solar (SODIS: solar desinfection).

O delineamento experimental utilizado foi o de blocos casualizados, em esquema fatorial (5 x 2), com cinco repetições totalizando cinquenta unidades experimentais. Os tratamentos foram: 100\% água residuária bruta (ARB); 100\% água residuária filtrada em filtro de areia (ARF); 100\% água SODIS (Solar disinfection) (ARS); $50 \%$ da água residuária filtrada e 50\% com água SODIS (ARFS); água de abastecimento (testemunha) (AA) e duas épocas de avaliações 100 e 120 DAP (dias após o plantio).

As mudas de tomate (variedade Santa Clara) foram transplantadas para vasos de $20 \mathrm{~L}$ aos 25 dias após o plantio (DAP), quando houve a formação de cinco folhas definitivas da muda de tomateiro.
Para esse estudo foram usados 4 lisímetros de pesagem com célula de carga construídos de chapa metálica galvanizada com espessura de $2 \mathrm{~mm}$ com dreno constituído de tubo PVC de 3/4" e válvula de abertura na parte inferior. Os lisímetros foram dispostos em paralelo entre si, sendo que as unidades da extremidade possuem dimensões de $0,80 \mathrm{~m}$ de diâmetro por $0,75 \mathrm{~m}$ de altura e os 2 centrais $0,70 \mathrm{~m}$ de diâmetro e mesma altura dos demais, cujas áreas correspondem a 0,503 e $0,385 \quad \mathrm{~m}^{2}$ respectivamente.

Cada lisímetro de pesagem mecânica é composto de 3 células de carga, dispostas em forma triangular, modelos L-500 (externos) e GL-200 (internos) de capacidades iguais a 500,0 e 200,0 Kg respectivamente, caixa de junção modelo 4134 e módulo indicador de pesagem modelo 3101-CP.

O sistema de armazenamento de dados é composto de um “data logger” modelo CR1000 da fabricante Campbell Scientific conectado ao módulo indicador de pesagem de cada lisímetro. O CR1000 foi conectado a uma bateria auxiliar e esta, por sua vez, a um carregador de bateria 
ligado a corrente contínua, todos acondicionados em abrigo próprio.

A lâmina aplicada foi determinada de acordo com a parcela de evaporação de água no solo contido nos lisímetros de pesagem, sendo que cada lisímetro foi submetido a $100 \%$ da reposição hídrica (RH) quando da capacidade de água disponível no solo (CAD).

O número de frutos foi obtido pela contagem, com resultados expressos por planta. O comprimento do fruto foi obtido medindo-se com um paquímetro digital eletrônico do tipo "bico fino" (ponta aguda) com precisão de 0,01 $\mathrm{mm}$, do ápice a base do fruto, e o diâmetro do fruto através do mesmo paquímetro digital eletrônico na região equatorial perpendicular ao comprimento. O peso do fruto foi avaliado após a colheita através de uma balança de pesagem, e posteriormente foi obtida a produtividade.

Os dados obtidos foram submetidos à análise de variância pelo teste F, e em caso de significância as médias foram comparadas entre si pelo teste de Tukey a 5\% de probabilidade, usando o programa estatístico SISVAR (FERREIRA, 2011).

\section{RESULTADOS E DISCUSSÃO}

No resumo da análise de variância, observa-se que houve interação significativa ao nível de $1 \%$ de probabilidade entre os fatores tipos de águas (TAG) e dias após o plantio (DAP) para as variáveis número de frutos, peso dos frutos, comprimento dos frutos, diâmetro dos frutos e número de botões florais, $\mathrm{O}$ fator tipos de águas (TAG) foi significante ao nível de $1 \%$ de probabilidade para a produtividade do tomate. O coeficiente de variação das variáveis foi no máximo de 9,8\% (Tabela 2). Sorgato et al. (2015) verificaram que o comprimento do fruto (CFR) e o peso do fruto (PFR) não foram influenciadas $(\mathrm{P}>0,05)$ pelo DAP.

Tabela 2. Resumo da análise de variância número de frutos (NFR), peso dos frutos (PFR), comprimento dos frutos (CFR), diâmetro dos frutos (DFR), número de botões florais (NBFL) e produtividade (PROD) do tomate.

\begin{tabular}{cccccccc}
\hline \multirow{2}{*}{ FV } & \multirow{2}{*}{ GL } & \multicolumn{7}{c}{ QM $^{1}$} \\
\cline { 3 - 7 } & & NFR & PFR & CFR & DFR & NBFL & PROD \\
\hline TAG & 4 & $118,90^{* *}$ & $178,28^{* *}$ & $21,60^{* *}$ & $36,85^{* *}$ & $102,82^{* *}$ & $1,54^{* *}$ \\
Resíduo (a) & 36 & 0,58 & 8,54 & 3,26 & 2,08 & 0,22 & 0,01 \\
DAP & 1 & $388,09^{* *}$ & $165904,29^{* *}$ & $1808,54^{* *}$ & $3297,74^{* *}$ & $201,64^{* *}$ & - \\
TAG*DAP & 4 & $45,39^{* *}$ & $226,87^{* *}$ & $22,81^{* *}$ & $25,90^{* *}$ & $9,16^{* *}$ & - \\
Resíduo (b) & 54 & 0,38 & 9,10 & 2,71 & 2,49 & 0,19 & - \\
\hline CV a (\%) & 5,14 & 5,64 & 4,03 & 3,03 & 9,76 & 6,16 \\
\hline CV b (\%) & 4,15 & 5,82 & 3,67 & 3,32 & 9,19 & - \\
\hline${ }^{1}$ Tipos de águas (TAG), Dias após o plantio (DAP), CV (Coeficiente de variância). ${ }^{* *}$ e $^{*}$ significativo a 1 e 5\% de \\
probabilidade, respectivamente, ns não significativo pelo teste F a 5\% de probabilidade.
\end{tabular}

O número de botões florais do tomateiro verificado no tipo de $100 \%$ água residuária bruta foi 16,$48 ; 34,07$ e $76,92 \%$ maior do que o número de botões florais observado no tipo de água residuária SODIS, água residuária 50\% filtrada e 50\% SODIS e água de abastecimento aos 100 dias após o plantio, respectivamente. Aos 120 dias após o plantio o número de botões florais do tomateiro observado no tipo de água residuária SODIS foi 25; 67,86 e 89,29\% maior do que o número de botões florais observado no tipo de água residuária filtrada, água residuária
$50 \%$ filtrada e $50 \%$ SODIS e água de abastecimento, respectivamente (Tabela 3). Segundo Silva et al. (2013) sob déficit hídrico ocorre uma taxa de aborto floral de $54,24 \%$, ao passo que este índice foi de $76,43 \%$ na lâmina estimada de $140 \%$ da ETc; o abortamento de flores e queda dos botões florais ocorre devido a períodos secos prolongados ou ao manejo errado da irrigação (ALVARENGA, 2004).

O número de frutos do tomateiro verificado no tipo de água residuária filtrada foi $18,52 \%$ maior do que o número de frutos 
observado no tipo de água de abastecimento aos 100 dias após o plantio (Tabela 3). Hafle et al. (2009) verificaram aumentos de 7,5\% no número de frutos. Aos 120 dias após o plantio o número de frutos do tomateiro observado no tipo de água residuária bruta foi 19,90; 7,28; 15,05 e $49,51 \%$ maior do que o número de frutos observado no tipo de água residuária filtrada, água residuária SODIS, água residuária 50\% filtrada e 50\% SODIS e água de abastecimento, respectivamente. Conforme Alves et al. (2015) o número de frutos apresentou incrementos significativos, com diferença de até $18,8 \%$; estes autores também salientam que uma maior produção não implica obrigatoriamente em maior produtividade, uma vez que outros fatores, tais como densidade, tamanho e número de frutos, também influenciam a produtividade da cultura.
O comprimento do fruto do tomate observado no tipo de água residuária 50\% filtrada e $50 \%$ SODIS foi $6,93 \%$ maior do que o comprimento do fruto observado no tipo de água residuária filtrada aos 100 dias após o plantio. Aos 120 dias após o plantio o comprimento do fruto do tomate verificado no tipo de água residuária SODIS foi 4,41 e $7,65 \%$ maior que o comprimento do fruto observado no tipo de água residuária bruta e água de abastecimento, respectivamente (Tabela 3). Segundo Silva et al. (2013) há correlação positiva e significativa entre comprimento do fruto com a massa da matéria fresca do fruto e da massa da matéria fresca do fruto com o número de sementes por fruto $\mathrm{e}$ comprimento do fruto com o número de sementes por fruto.

Tabela 3. Médias do número de botões florais (NBFL), número de frutos (NFR) e comprimento do fruto do tomate (CFR) para a água residuária bruta (ARB), água residuária filtrada (ARF), água residuária SODIS (ARS), água 50\% de água residuária filtrada e 50\% de água residuária SODIS (ARFS), água de abastecimento (AA).

\begin{tabular}{ccccccc}
\hline \multirow{2}{*}{ Tipos } & \multicolumn{9}{c}{ DAP $^{1}$} \\
\cline { 2 - 7 } águas & \multicolumn{2}{c}{ NBFL } & \multicolumn{2}{c}{ NFR } & \multicolumn{2}{c}{ CFR (mm) } \\
\cline { 2 - 7 } & 100 & 120 & 100 & 120 & 100 & 120 \\
\hline ARB & $9,10 \mathrm{a}$ & $4,70 \mathrm{~b}$ & $13,30 \mathrm{a}$ & $20,60 \mathrm{a}$ & $41,70 \mathrm{a}$ & $48,67 \mathrm{bc}$ \\
ARF & $6,30 \mathrm{c}$ & $4,20 \mathrm{~b}$ & $13,50 \mathrm{a}$ & $16,50 \mathrm{~d}$ & $38,96 \mathrm{~b}$ & $48,30 \mathrm{c}$ \\
ARS & $7,60 \mathrm{~b}$ & $5,60 \mathrm{a}$ & $13,30 \mathrm{a}$ & $19,10 \mathrm{~b}$ & $39,44 \mathrm{~b}$ & $50,91 \mathrm{a}$ \\
ARFS & $6,00 \mathrm{c}$ & $1,80 \mathrm{c}$ & $13,30 \mathrm{a}$ & $17,50 \mathrm{c}$ & $41,86 \mathrm{a}$ & $50,62 \mathrm{ab}$ \\
AA & $2,10 \mathrm{~d}$ & $0,60 \mathrm{~d}$ & $11,00 \mathrm{~b}$ & $10,40 \mathrm{e}$ & $41,03 \mathrm{ab}$ & $47,02 \mathrm{c}$ \\
\hline
\end{tabular}

${ }^{1}$ Dias após o plantio (DAP); médias com a mesma letra minúscula na coluna não indica diferença significativa pelo teste Tukey, a 5\% de probabilidade.

O diâmetro dos frutos do tomate verificado no tipo de água de abastecimento foi 10,08 e 5,63\% maior do que o diâmetro dos frutos observado no tipo de água residuária filtrada e água residuária SODIS aos 100 dias após o plantio, respectivamente.

Aos 120 dias após o plantio o diâmetro dos frutos do tomate verificado no tipo de água residuária SODIS foi 4,35; 7,49 e 6,79\% maior do que o diâmetro dos frutos observado no tipo de água residuária bruta, água residuária filtrada e água de abastecimento, respectivamente. Genuncio et al., (2009) constataram um decréscimo significativo no diâmetro de frutos, além disso observaram que a relação $\mathrm{N}: \mathrm{K}$ de 1,2 aumenta a massa e o diâmetro de frutos comerciais da cultivar San Marzano, indicando que a relação $\mathrm{N}: \mathrm{K}$ de 1:2 propicia, para esta cultivar, a obtenção de frutos de maior qualidade comercial. O diâmetro dos frutos do tomate verificado no tipo de água residuária 50\% filtrada e 50\% SODIS foi 5,57 e $4,86 \%$ maior que o diâmetro dos frutos observado no tipo de água residuária filtrada e água de abastecimento aos 120 dias após o plantio, respectivamente (Tabela 4).

Não houve diferença significativa para a variável peso dos frutos do tomate entre os tipos de águas aplicadas aos 100 dias após o plantio. Aos 120 dias após o plantio o peso dos frutos do tomate verificado no tipo de água residuária SODIS foi 11,$16 ; 15,92 ; 6,38$ e $11,59 \%$ maior 
do que o peso dos frutos observado no tipo de água residuária bruta, água residuária filtrada, água residuária 50\% filtrada e 50\% SODIS e água de abastecimento, respectivamente (Tabela 4). Thebaldi et al. (2013) observou que o tratamento com efluente foi o que apresentou os frutos mais pesados, embora sem diferirem dos demais tratamentos. Medeiros (2012) notou também que a água residuária teve influência no peso, tendo em vista que plantas irrigadas com níveis de $100 \%$ de água têm frutos com pesos semelhantes; entretanto, plantas com maior restrição hídrica $50 \%$ têm médias significativamente inferiores.

Tabela 4. Médias do diâmetro do fruto (DFR), peso dos frutos (PFR) e produtividade (PROD) do tomate, para a água residuária bruta (ARB), água residuária filtrada (ARF), água residuária SODIS (ARS), água 50\% de água residuária filtrada e 50\% de água residuária SODIS (ARFS), água de abastecimento (AA).

\begin{tabular}{ccccc}
\hline \multirow{2}{*}{ Tipos de águas } & \multicolumn{3}{c}{ DAP $^{1}$} \\
\cline { 2 - 5 } & \multicolumn{2}{c}{ DFR $(\mathrm{mm})$} & 100 & PFR (g) \\
\cline { 2 - 5 } & $42,48 \mathrm{ab}$ & $53,21 \mathrm{bc}$ & $12,33 \mathrm{a}$ & $90,38 \mathrm{c}$ \\
ARB & $39,11 \mathrm{c}$ & $51,46 \mathrm{c}$ & $9,68 \mathrm{a}$ & $85,54 \mathrm{~d}$ \\
ARF & $41,05 \mathrm{bc}$ & $55,63 \mathrm{a}$ & $9,14 \mathrm{a}$ & $101,73 \mathrm{a}$ \\
ARS & $43,08 \mathrm{a}$ & $54,50 \mathrm{ab}$ & $12,34 \mathrm{a}$ & $95,24 \mathrm{~b}$ \\
ARFS & $43,50 \mathrm{a}$ & $51,85 \mathrm{c}$ & $12,02 \mathrm{a}$ & $89,94 \mathrm{c}$ \\
AA & &
\end{tabular}

${ }^{1}$ Dias após o plantio (DAP); médias com a mesma letra minúscula na coluna não indica diferença significativa pelo teste Tukey, a 5\% de probabilidade.

O número de botões florais do tomateiro verificado aos 100 dias após o plantio foi 48,35; 33,33; 26,32; 70 e $71,43 \%$ maior do que o número de botões florais observado aos 120 dias após o plantio para o tipo de água residuária bruta, água residuária filtrada, água residuária
SODIS, água residuária 50\% filtrada e 50\% SODIS e água de abastecimento, respectivamente (Figura 1). Em relação ao número de botões florais Grigolli et al. (2015) ressaltou que houve interação significativa entre as cultivares somente aos 77 e 91 DAR.

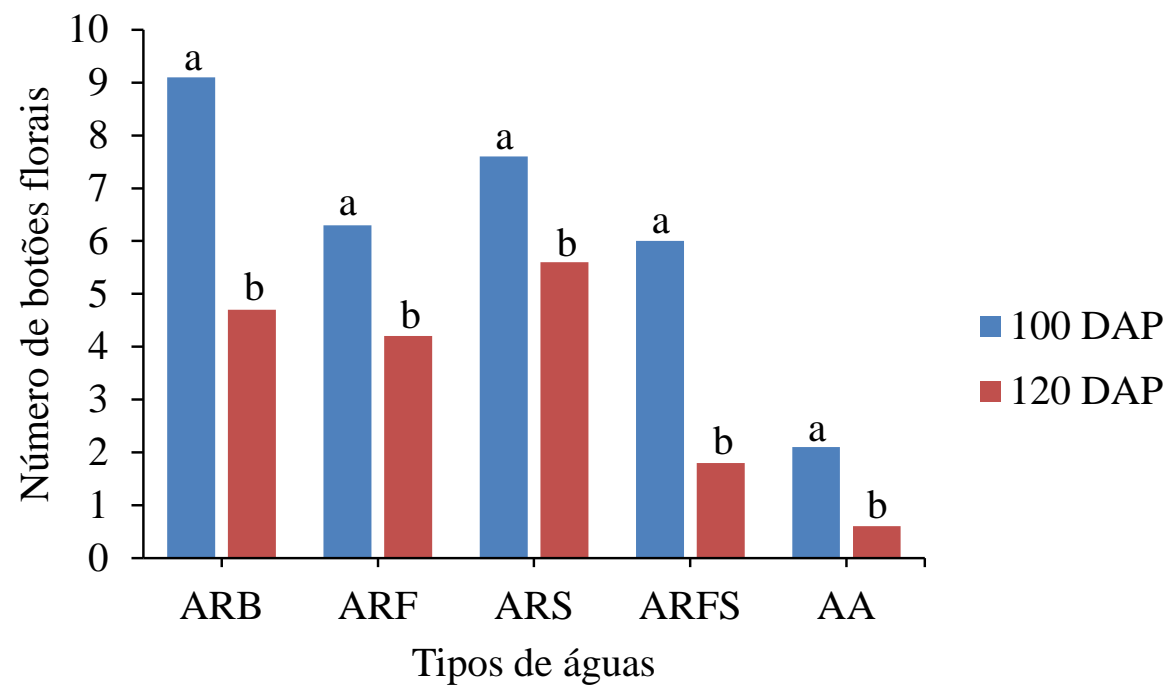

Figura 1. Número de botões florais em função dos tipos de águas aos 100 e 120 DAP.

O número de frutos do tomateiro verificado aos 120 dias após o plantio foi 35,44; 18,18; 30,37; 24 e 5,45\% maior do que o número de frutos observado aos 100 dias após o plantio para o tipo de água residuária bruta, água residuária filtrada, água residuária SODIS, água 
residuária 50\% filtrada e 50\% SODIS e água de abastecimento, respectivamente (Figura 2). Segundo Silva et al. (2010) O número de frutos apresentou aumento progressivo até os 280 DAP, alcançando cerca $33 \%$ durante a fase de colheita.

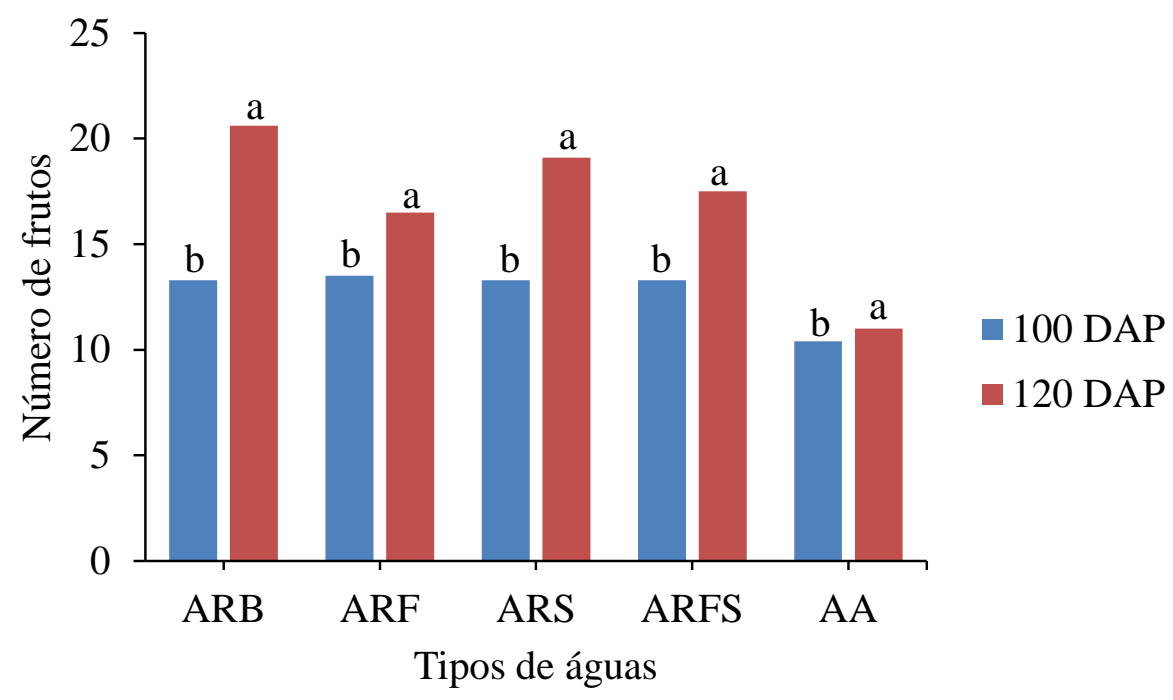

Figura 2. Número de frutos em função dos tipos de águas aos 100 e 120 DAP.

O comprimento do fruto do tomate verificado aos 120 dias após o plantio foi 14,32; 19,33; 22,54; 17,30 e $12,74 \%$ maior do que o comprimento do fruto observado aos 100 dias após o plantio para o tipo de água residuária bruta, água residuária filtrada, água residuária
SODIS, água residuária 50\% filtrada e 50\% SODIS e água de abastecimento, respectivamente (Figura 3). Garcia (2015) observou que o comprimento do fruto foi afetado positivamente com o aumento do tempo em que a cultura recebeu irrigação.

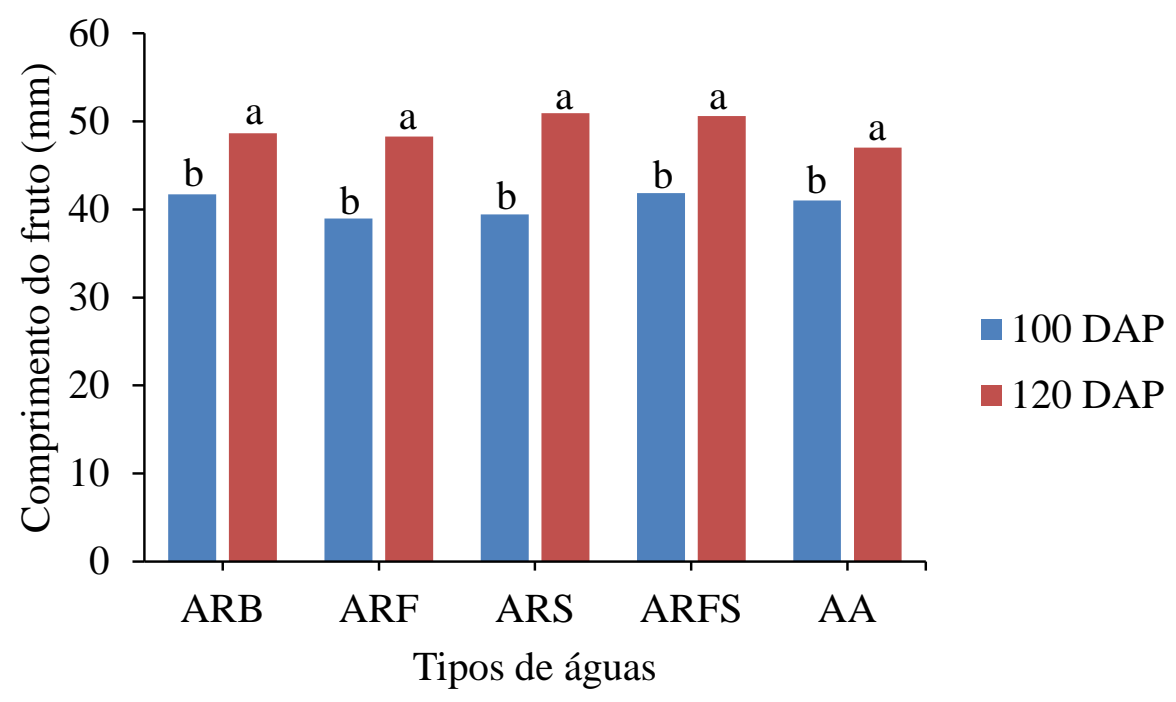

Figura 3. Comprimento do fruto em função dos tipos de águas aos 100 e 120 DAP.

O diâmetro do fruto do tomate verificado aos 120 dias após o plantio foi 20,17; 24; 26,21; 20,96 e $16,10 \%$ maior do que o diâmetro do fruto observado aos 100 dias após o plantio para o tipo de água residuária bruta, água residuária filtrada, água residuária SODIS, água residuária $50 \%$ filtrada e $50 \%$ SODIS e água de abastecimento, respectivamente (Figura 4). Marques et al. (2011) observaram correlações positivas do comprimento do fruto e diâmetro do 
fruto com as maiores dimensões da folha portanto, uma vez que essas características foliares incrementaram as dimensões dos frutos, houve reflexo direto destas dimensões sobre o incremento na produtividade de frutos.

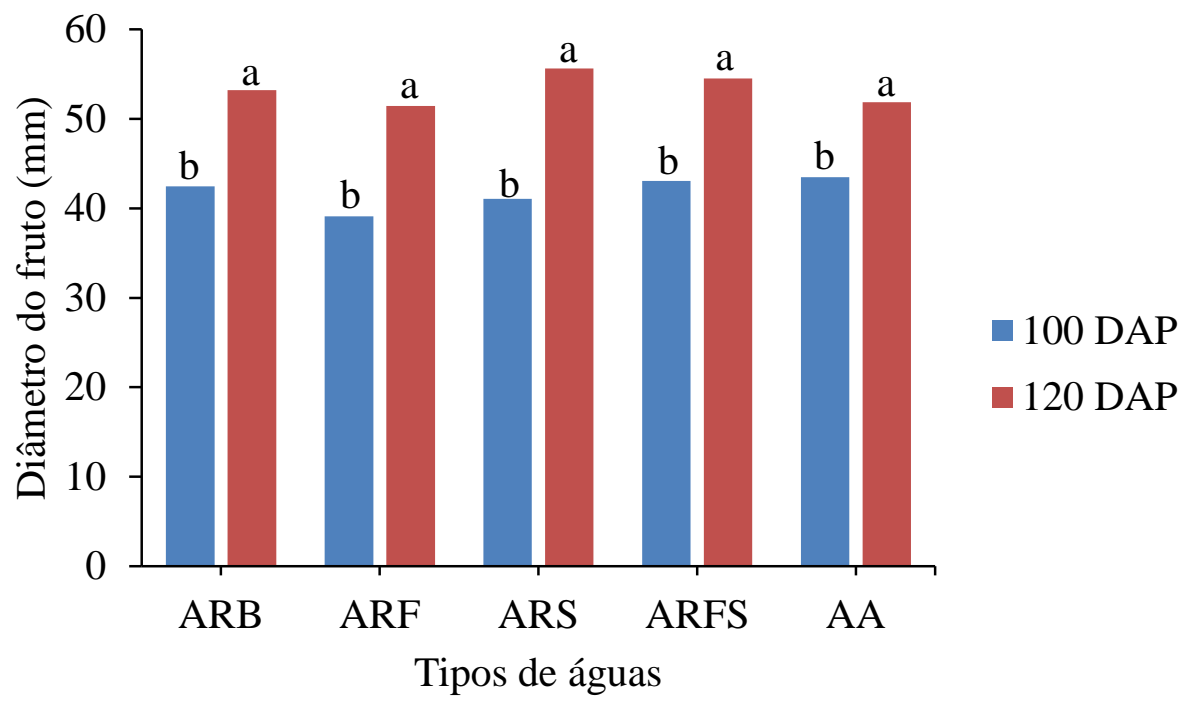

Figura 4. Diâmetro do fruto em função dos tipos de águas aos 100 e 120 DAP.

$\mathrm{O}$ peso do fruto do tomate verificado aos 120 dias após o plantio foi 86,36; 88,69; 91,$01 ; 87,04$ e $86,63 \%$ maior do que o peso do fruto observado aos 100 dias após o plantio para o tipo de água residuária bruta, água residuária filtrada, água residuária SODIS, água residuária 50\% filtrada e 50\%
SODIS e água de abastecimento, respectivamente (Figura 5). Reis et al. (2013) encontrou valores próximos aos observados nesse trabalho de número de frutos por planta, peso do fruto e produtividade da cultua do tomate, em condições de ambiente protegido.

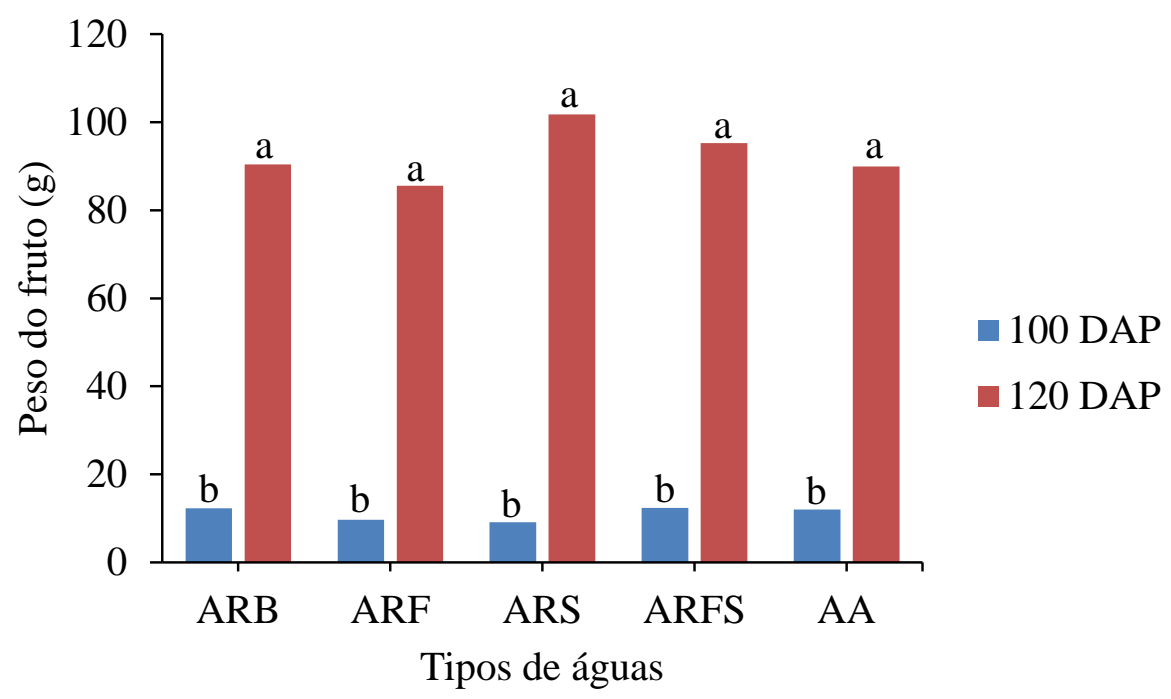

Figura 5. Peso do fruto em função dos tipos de águas aos 100 e 120 DAP.

A produtividade do tomate verificada no tipo de água residuária bruta foi 29,07; 14,53 e $59,98 \%$ maior do que a produtividade observada no tipo de água residuária filtrada, água residuária 50\% filtrada e 50\% SODIS e água de abastecimento, respectivamente (Figura 6). 
Thebaldi et al. (2013) observou que a produtividade com efluente foi $21,8 \%$ maior do que a fertirrigação e 26,13\% maior que o tratamento com água.

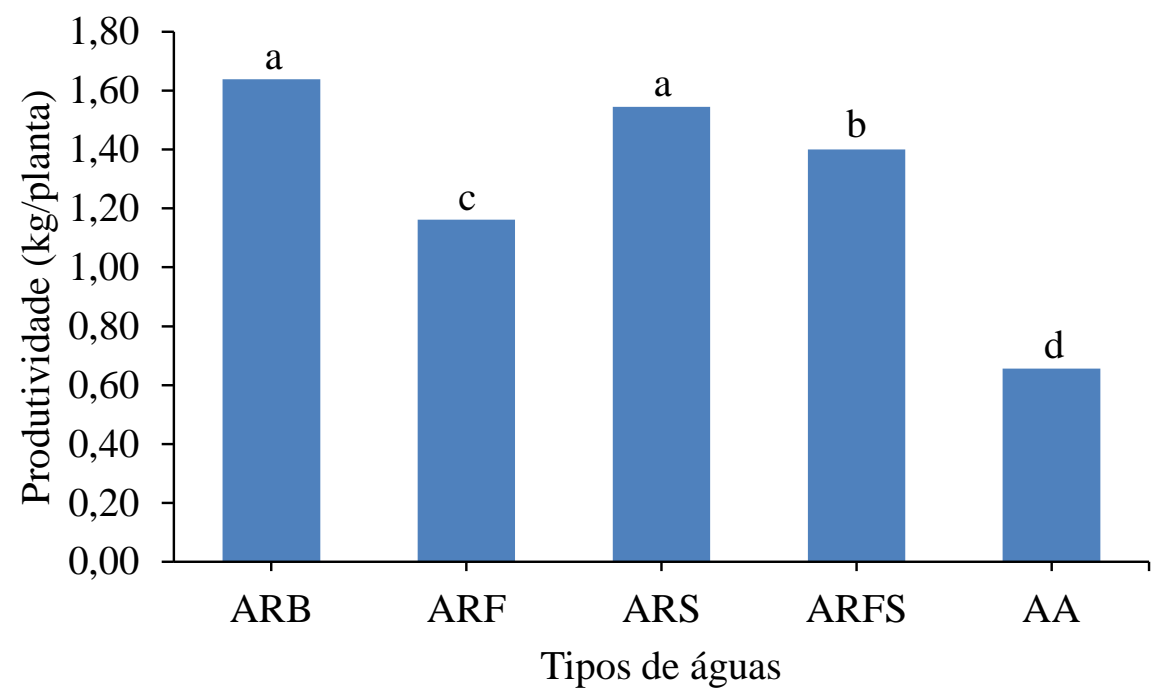

Figura 6. Produtividade do tomate em função dos tipos de águas.

\section{CONCLUSÕES}

A água residuária bruta proporciona maior incremento no número de botões florais, número de frutos, comprimento e diâmetro dos frutos, peso dos frutos para o tomate, seguida água residuária SODIS, água residuária 50\% filtrada e 50\% SODIS, água resdiuária filtrada e água de abastecimento. A produtividade é maior para a água residuária bruta com diferença de até $60 \%$ quando comparada com a água de abastecimento.

A aplicação de água residuária bruta de suinocultura promove incrementos consideráveis no crescimento e desenvolvimento da cultura do tomate, sendo uma boa opção para a nutrição do tomateiro.

\section{AGRADECIMENTO}

Os autores agradecem ao Conselho Nacional de Desenvolvimento Científico e Tecnológico (CNPq), à Coordenação de Aperfeiçoamento de Pessoal de Nível Superior (Capes) e ao Instituto Federal Goiano - Campus Rio Verde, pelo apoio financeiro e estrutural.

\section{REFERÊNCIAS}

AGRIANUAL. Consultoria e comércio. Anuário da agricultura brasileira. FNP, São Paulo. 2008.

ALVARENGA, M.A.R. Produção em campo, em casa de-vegetação e em hidroponia. Universidade Federal de Lavras, Lavras. 2004. p. 1-400.

ALVES, G.S.; TARTAGLIA, F.L.; BELTRÃO, N.E.M.; SAMPAIO, L.R.; FREIRE, M.A.O. Densidade populacional e seu efeito na produtividade da mamoneira BRS Energia sob cultivo irrigado. Centro de Ciências Agrárias Universidade Federal do Ceará, Fortaleza, CE. Revista Ciência Agronômica, v. 46, n. 3, p. 546-554, 2015.

EMBRAPA. Sistema Brasileiro de Classificação de Solo. Empresa brasileira de pesquisa agropecuária. 3.ed. Rio de Janeiro, Centro Nacional de Pesquisa de Solos, 2013. 353p.

FERREIRA, D.F. Sisvar: a computer statistical analysis system. Ciência e Agrotecnologia, 
Unversidade Federal de Lavras, v. 35, n. 6, p. 1039-1042, 2011.

GARCIA, A.C. Supressão e frequência da irrigação na cultura da abobrinha. 2015. $66 \mathrm{f}$. Dissertação (Mestrado - Centro de Ciências Agrárias), Departamento de Engenharia Agrícola, Universidade Federal do Ceará, Fortaleza-CE.

GENUNCIO, G.C. Crescimento e produção do tomateiro em sistemas de cultivo a campo, hidropônico e fertirrigado, sob diferentes doses de nitrogênio e potássio. 2009. 150 f. Tese (Doutorado - Instituto de Agronomia), Universidade Federal Rural do Rio de Janeiro.

GRIGOLLI, J.F.J.; CROSARIOL NETTO, J.; IZEPPI, T.S.; SOUSA, L.A.; FRAGA, D.F.; BUSOLI, A.C. Infestação de Anthonomus grandis (coleoptera: curculionidae) em rebrota de algodoeiro. Pesquisa Agropecuária Tropical, Goiânia. v. 45, n. 2, p. 200-208, 2015.

HAFLE, O.M.; RAMOS, J.D.; LIMA, L.C.O.; FERREIRA, E.A.; MELO, P.C. Produtividade e qualidade de frutos do maracujazeiro-amarelo submetido à poda de ramos produtivos. Revista Brasileira de Fruticultura, Jaboticabal - SP. v. 31, n. 3, p. 763-770, 2009.

IBGE. Levantamento Sistemático da Produção Agrícola. Pesquisa mensal de previsão e acompanhamento das safras agrícolas no ano civil. Rio de Janeiro. v. 29, n. 2, p. 1-79, 2016.

KÖPPEN, W. Köppen climate classification. Geography about. (2013). Disponível em: $<$ http://geography.about.com/library/weekly/aa 011700b.htm >. Acessado em: 2 Novembro. 2016.

MACHADO NETO A. S. Viabilidade agroeconômica da produção de tomate de 'mesa' sob diferentes sistemas de cultivo e manejo de adubação. 2014. 108 f. Universidade Estadual do Norte Fluminense Darcy Ribeiro.
MAROUELLI, W.A.; SILVA, H.R.; SILVA, W.L.C. Irrigação do tomateiro para processamento. Embrapa, Brasília. p. 1-24, 2012.

MARQUES, L.S.; ANDREOTTI, M.; BUZETTI, S.; ISEPON, J.S. Produtividade e qualidade de abacaxizeiro cv. smooth cayenne, cultivado com aplicação de doses e parcelamentos do nitrogênio, em Guaraçaí-SP. Revista Brasileira de Fruticultura, Jaboticabal - SP. v. 33, n. 3, p. 1004-1014, 2011.

MEDEIROS, S.S. Crescimento e produção do pinhão manso sob adubação fosfatada $e$ irrigação com água residuária. 2012. $74 \mathrm{f}$. Tese (Doutorado) - Centro de Tecnologia e Recursos Naturais, Universidade Federal de Campina Grande.

MEDEIROS, S.S.; GHEYI, H.R.; PÉREZMARIN, A.M.; SOARES, F.A.L.; FERNANDES, P.D. Características químicas do solo sob algodoeiro em área que recebeu água residuária da suinocultura. Revista Brasileira de Ciência do Solo, Viçosa. v. 35, p. 10471055, 2011.

MEDEIROS, S.S.; SOARES, F.A.L.; GHEYI, H.R.; FERNANDES, P.D. Uso de água residuária de origem urbana no cultivo de gérberas: efeito nos componentes de produção. Engenharia Agrícola. v. 27, n. 2, p. 569-578, 2007.

REIS, L.S.; AZEVEDO, C.A.V.; ALBUQUERQUE, A.W.; JUNIOR, J.F.S. Índice de área foliar e produtividade do tomate sob condições de ambiente protegido. Revista Brasileira de Engenharia Agrícola e Ambiental. v. 17, n. 4, p. 386-391, 2013.

SAMPAIO, A.C.; FUMIS, T.F.; LEONEL, S. Crescimento vegetativo e características dos frutos de cinco cultivares de abacaxi na região de Bauru-SP. Revista Brasileira de Fruticultura. v. 33, n. 3, p. 816-822, 2011.

SILVA, J.M.; FERREIRA, R.S.; MELO, A.S.; SUASSUNA, J.F.; DUTRA, A.F.; GOMES, J.P. 
Cultivo do tomateiro em ambiente protegido sob diferentes taxas de reposição da evapotranspiração. Revista Brasileira de Engenharia Agrícola e Ambiental. v. 17, n. 1, p. 40-46, 2013.

SILVA, M.M.; BROETTO, S.G.; VALBÃO, S.C.; COSTA, A.F.S.; SILVA, D.M. Características vegetativas e de frutos de mamoeiros obtidos por seleção massal. Semina: Ciências Agrárias, Londrina. v. 31, n. 1, p. 2938, 2010.

SILVA, M.S.; BORGES, E.E.L.; LEITE, H.G.; CORTE, V.B. Biometria de frutos e sementes de Melanoxylon brauna schott. (fabaceaecaesalpinioideae). Cerne, Lavras. v. 19, n. 3, p. 517-524, 2013.

SORGATO, J.C.; SOARES, J.S.; PINTO, J.V.C.; ROSA, Y.B.C.J. Potencial germinativo de sementes e qualidade de keikis de
Dendrobium nobile em diferentes fases do desenvolvimento dos frutos. Ciência Rural, Santa Maria. v. 45, n. 11, p. 1965-1971, 2015.

SOUZA, J.A.R.; MOREIRA, D.A.; FERREIRA, P.A.; MATOS, A.T. Avaliação de frutos de tomate de mesa produzidos com efluente do tratamento primário da água residuária da suinocultura. Engenharia na Agricultura, Viçosa. v. 18, n. 3, p. 198-207, 2010.

THEBALDI, M.S.; ROCHA, M.S.; SANDRI, D.; FELISBERTO, A.B. Características produtivas do tomate irrigado por diferentes sistemas de irrigação e qualidades de água. Irriga, Botucatu. v. 18, n. 1, p. 43-58, 2012.

VIELMO, H. Dejeto líquido de suínos na adubação de pastagem de tifton 85. 2008. 125 f. Tese (Doutorado - Universidade Federal do Paraná), Curitiba. 